\title{
Studi Pengelolaan Sampah Berbasis Komunitas pada Kawasan Permukiman Perkotaan di Yogyakarta
}

\author{
Amos Setiadi1 \\ Yogyakarta \\ Artikel Masuk : 3 Maret 2015 \\ Artikel Diterima : 9 April 2015
}

Magister Teknik Arsitektur, Universitas Atma Jaya

\begin{abstract}
Abstrak: Pelaksanaan fasilitasi dan stimulasi pengelolaan sampah ramah lingkungan dengan pola $3 \mathrm{R}$ berbasis masyarakat dihadapkan pada masalah terbatasnya sarana dan prasarana serta belum berkembangnya mekanisme insentif dan disinsentif. Pengelolaan sampah oleh kelompok masyarakat mulai berkembang namun belum signifikan baik cakupan dan skala layanan. Penelitian ini merupakan penelitian deskriptif dan bersifat kualitatif, bertumpu pada pengumpulan data primer dan sekunder.Analisis data mengacu peraturan terkait persampahan. Penarikan kesimpulan dilakukan dengan cara deduktif. Hasil analisis menunjukkan melalui pendekatan partisipatif, masyarakat mampu mengidentifikasi, menganalisis dan memetakan sendiri masalah, potensi, ancaman, dan hambatan masalah sampah; serta menemukan solusi masalah sampah. Dalam mengelola sampah, masyarakat mampu mengorganisir diri dalam kegiatan bersama untuk memecahkan masalah sampah, sebagai bentuk kesadaran tinggi dalam merespon masalah sampah dan bertindak atas dasar kepentingan bersama.
\end{abstract}

Kata Kunci: komunitas, partisipatif, pola 3R, sampah

\begin{abstract}
Facilitation and stimulation on the environmentally friendly waste management withthe Triple- $R$ community-based pattern dealwith the problems of limited infrastructure and the lack of incentive and disincentive mechanisms. The waste management organized by the communities actually has developed even though the scope and scale of service remain low. This research applies descriptive and qualitative approaches in nature by using both primary and secondary data collection. The data analysis refers to the relevant waste regulations. The concluding inferences are drawn deductively. The results show that the participatory approach implementation is useful to enabling the local community in conducting self-identification, analysis, and mapping of the actual problems, potentials, threats, and obstacles related to waste management; hence, they could find the appropriate solutions. In fact, they are able to conduct self-organizing practice through collective actions necessary to waste problem solving, which have already been manifested in their higher awareness on responding the waste problems for the sake of mutual interests.
\end{abstract}

Keywords: community, participatory, $3 R$ pattern, trash

\footnotetext{
${ }^{1}$ Korespondensi Penulis: Magister Teknik Arsetektur, Universitas Atma Jaya, Yogyakarta Email: amos.setiadi@yahoo.com
} 


\section{Pendahuluan}

Sampah adalah sisa kegiatan sehari-hari manusia dan/atau proses alam yang berbentuk padat (UU No 18/2008 Pasal 1). Timbulan sampah pada permukiman perkotaan berasal dari rumah tangga, warung, bangunan umum, dan industri rumah tangga. Pertumbuhan penduduk di kawasan permukiman perkotaan menimbulkanpermasalahanpengelolaan sampah mulai dari masalah timbulan sampah, kebutuhan tempat pemrosesan akhir sampah, serta biaya lingkungan yang ditimbulkan. Pengelolaan sampah adalah kegiatan yang sistematis, menyeluruh, dan berkesinambungan yang meliputi pengurangan dan penanganan sampah. Model pengelolaan sampah yang dikenal saat ini antara lain; penimbulan sampah, penanganan di tempat, pengumpulan, pengangkutan, pengolahan, dan pemrosesan akhir (Faizah, 2008; Widyatmoko \& Moerdjoko, 2002).

Penimbulan sampah memerlukan penanganan yang tepat berdasarkan jumlah pelaku, jenis dan kegiatannya. Penanganan di tempat atau penanganan sampah pada sumbernya merupakan perlakuan terhadap sampah yang masih memiliki nilai ekonomis yang dilakukan sebelum sampah sampai di tempat pembuangan. Penanganan sampah ditempat memberi pengaruh signifikan terhadap penanganan sampah pada tahap berikutnya. Kegiatan penanganan meliputi pemilahan, pemanfaatan kembali (reuse) dan daur ulang (recycle) bertujuan untuk mereduksi besarnya timbulan sampah (reduce). Pengumpulan sampah merupakan kegiatan yang dilakukan dari rumah-rumahatau sumber timbulan sampah menuju ke Tempat Penampungan Sementara (TPS) sebelum dilakukan pengangkutan atau pemindahan sampah dari TPS kelokasi pemrosesan akhir (TPA).

Pengolahan sampah meliputiproses transformasi fisik berupa pemisahan komponen sampah dan pemadatan untuk mempermudah penyimpanan dan pengangkutan. Pembakaran untuk mengubah sampah menjadi bentuk gas sehingga volumenya dapat berkurang hingga 95\%. Pembuatan kompos (composting) pupuk alami dari sampah hijaudan bahan organik lain untuk mempercepat proses pembusukan, serta transformasi sampah menjadi energi panas maupun listrik. Sedangkan pemrosesan akhir sampah merupakan penempatan sampah di tempat tertentu (open dumping, sanitary landfill) hingga kapasitas tempat tidak lagi mencukupi.

Di Kabupaten Bantul, Daerah Istimewa Yogyakarta, volume sampah yang dihasilkan oleh 215.678 keluarga mencapai $2.190,43 \mathrm{~m}^{3}$ per-hari, sedangkan volume sampah yang terangkut 131,37 $\mathrm{m}^{3}$ atau 6,00\% (BLH Kabupaten Bantul, 2011). Berdasarkan SNI S-041993-03 tentang spesifikasi timbulan sampah untuk kota kecil dan kota sedang, maka besarnya timbulan sampah diKabupaten Bantul sebagai kota sedang adalah sebesar 2,753,25 liter/orang/hari atau 0,7-0,8 kg/orang/hari.Sebagian besar sampah (94\%) dikelola dengan caraon-site (ditimbun atau dibakar di halaman rumah) dan sisanya dibuang di sungai atau lahan-lahan kosong. Kedudukan Pemerintah Kabupaten Bantul sangat strategis dalam pelaksanaan fasilitasi dan stimulasi pengelolaan sampah ramah lingkungan dengan pola 3R berbasis masyarakat. Hal tersebut sesuai dengan UU No. 18 Tahun 2008 tentang Pengelolaan Sampah dan UU No. 32 Tahun 2009 tentang Perlindungan dan Pengelolaan Lingkungan Hidup, serta upaya peningkatan tanggung jawab masyarakat dan peluang pendapatan dari pengelolaan sampah.

UU No. 18 Tahun 2008 pasal 4 menyebutkan bahwa pengelolaan sampah bertujuan untuk meningkatkan kesehatan masyarakat dan kualitas lingkungan serta menjadikan sampah sebagai sumber daya. Pengelolaan sampah di Kabupaten Bantul mengadopsi konsep 3R, yaitureduce (mereduksi timbulan sampah), reuse (pemanfaatan kembali), dan recycle (daur ulang). Konsep 3R mendorong masyarakat melakukan penanganan sampah sejak dari sumbernya seperti pemilahan sampah dan pengemasan sampah dengan benar, mendorong penerapan konsep pemanfaatan sampah yang memiliki nilai ekonomi mulai dari pemulung hingga industri daur ulang sampah. Setiap rumah tangga memilah sampah mereka kedalam tiga tempat. Sampah plastik dikirim ke industri yang mengolah sampah 
plastik dan sampah kertas dikirim ke industri pengolah kertas sedangkan sampah organik diproses menjadi kompos.

Di Kabupaten Bantul, sarana dan prasarana pengelolaan sampah masih terbatas baik kualitas dan kuantitasnya, serta belum berkembangnya mekanisme insentif dan disinsentif di bidang pengelolaan sampah. Pengelolaan sampah oleh swasta atau kelompok masyarakat sudah mulai berkembang namun belum cukup signifikan dalam konteks cakupan dan skala layanan. Dengan adanya paradigma yang memandang sampah sebagai sumber daya yang dapat didaur-ulang sehingga menghasilkan nilai tambah, membuka peluang usaha dan lapangan kerja masyarakat di Kabupaten Bantul.

Peran Pemerintah Kabupaten Bantul menjamin terselenggaranya pengelolaan sampah yang baik dan berwawasan lingkungan. Pengelolaan sampah dikategorikan sebagai pelayanan publik, dan setiap warga memiliki hak dan kewajiban dalam mengelola sampah. Setiap rumah tangga wajib mengurangi sampah dan menanganinya dengan cara yang berwawasan lingkungan. Melalui studi identifikasi pengelolaan sampah berbasis komunitas ini diharapkan dapat mengetahui relevansi pengelolaan sampah dengan konsep 3R dalam membantu mengurangi timbulan sampah dan menciptakan peluang ekonomi dari daur ulang sampah di Kabupaten Bantul.

\section{Metodologi}

Penelitian ini merupakan penelitian deskriptif dan bersifat kualitatif, dilakukan dengan cara:

1. Pengumpulan data sekunder dan data primer yang mencakup data kependudukan dan data persampahan Kabupaten Bantul;

2. Data dianalisis dengan mengacu pada perundangan/peraturan terkait;

3. Penarikan kesimpulan dilakukan secara deduktif.

\section{Orisinalitas}

Penelitian tentang pengelolaan sampah dengan lokasi, metode dan kesimpulan yang berbeda dilakukan oleh:

a) Mifbakhuddin, Trixie Salawati, Arif Kasmudi (2010) meneliti adanya hubungan antara pendidikan, pengetahuan, dan pendapatan perkapita responden dengan pengelolaan sampah rumah tangga di Semarang;

b) Yenni Ruslinda, Shinta Indah, Widya Laylani (2012) meneliti sistem pengelolaan sampah, pengolahan sampah dengan cara composting, pembakaran tingkat tinggi (insinerasi), dan proses daur ulang sampah plastik dan kertas, efektif dilakukan di Kota Bukittinggi;

c) Ni Komang Ayu Artiningsih, Sudharto Prawata Hadi, Syafrudin (2012) meneliti pengelolaan sampah rumah tangga berbasis masyarakat di Sampangan (penerapan konsep 3R). Temuannya yaitu warga Jomblang belum seluruhnya bisa menerapkan konsep 3R karena belum semua warga ikut andil dalam pengelolaansampah tersebut. Tantangan utama penerapan konsep 3R antara lain kurangnya peran serta masyarakat, kurangnya sarana dan prasarana pendukung, kurangnya komunikasi antara pemerintah dengan lembaga terkait untuk mendukung peran serta masyarakat dalam pengelolaan sampah;

d) Riswan, Henna Rya Sunoko, Agus Hadiyarto (2011) meneliti pengelolaan sampah rumah tangga di Kecamatan Daha Selatan. Temuanya yaitutingkat pendidikan, tingkat pendapatan, perilaku terhadap kebersihan lingkungan, pengetahuan tentang perda persampahan, serta kesediaan membayar retribusi sampah berkorelasi positif dengan cara pengelolaan sampah rumah tangga; 
e) Bambang Munas Dwiyanto (2010) meneliti model peningkatan partisipasi masyarakat dalam pengelolaan sampah perkotaan. Tahapan penelitian dimulai dengan mengkaji pola pengelolaan sampah yang berlaku di Kelurahan Sambiroto, Kecamatan Tembalang, Kabupaten Semarang.Pendekatan yang dipakai untuk menyusun model Pengelolaan Sampah Terpadu Berbasis Masyarakat, yaitu pendekatan pemberdayaan masyarakat (community empowering) melalui peningkatan partisipasi stakeholder,

f) Viradin Yogiesti, Setiana Hariyani, Fauzul Rizal Sutikno (2010) meneliti bahwa pengelolaan sampah di Kota Kediri belum diikuti dengan keterlibatan masyarakat secara langsung karena adanya anggapan bahwa pengelolaan sampah ini merupakan tanggung jawab pemerintah. Dengan analisis multidimensional scaling (MDS) diketahui jenis pengolahan sampah komposting dan daur ulang kertas dipilih masyarakat;

g) Amalia Suzianti, Siti Humaira, dan Shabila Anjani (2013) meneliti sistem pengelolaan sampah di Jakarta, dengan pendekatan macroergonomic dan Analisis Makro Ergonomi dan Desain (MEAD) sebagai metode dalam pendekatan tersebut. Melalui pendekatan ini, dapat diketahui bahwa masalah utama dari sistem ini adalah kesalahan manusia dalam membuang sampah;

h) Tri Kharisma Jati (2013) meneliti peran pemerintah dalam pengelolaan sampah, yaitu sebagai regulator dan service provider. Penelitian dilakukan dengan teknik pengumpulan data, telaah dokumen dan kuesioner dan teknik analisis statistik deskripstif. Temuannya yaitu peran pemerintah sebagai regulator dan service provider dalam pengelolaan sampah lingkungan permukiman perkotaan masingmasing adalah sebesar $80 \%$ dan $61,67 \%$;

i) Haryono (2015) melakukan penelitian deskriptif kualitatif pada pengelolaan sampah di Kota Boyolali, baik yang dikelola oleh pemerintah dan warga yang didasarkan pada observasi, wawancara mendalam, dan dokumentasi. Teknik sampling yang digunakan adalah purposive sampling dan variasi maksimum. Diketahui bahwa mekanisme pengelolaan sampah di Boyolali cukup baik namun sangat tergantung pada proses 3P yang terdiri atas pengumpulan, pengangkutan, dan pembuangan, serta proses menumpuk, menyusun, dan penimbunan.

\section{Hasil dan Pembahasan}

Kabupaten Bantul memiliki luas 50.685 Ha, terdiri dari 17 kecamatan dan 75 desa. Perkembangan jumlah penduduk di Kabupaten Bantul dipengaruhi oleh pertumbuhan alami dan migrasi. Laju pertumbuhan penduduk rata-rata Kabupaten Bantul sebesar 1,57\%. Volume sampah di Kabupaten Bantul mencapai 2.190,43 $\mathrm{m}^{3}$ perhari, sedangkan volume sampah yang terangkut $131,37 \mathrm{~m}^{3}$ atau $6,00 \%$ dari total volume sampah. Tidak semua sampah diproses ke tempat pengolahan akhir (TPA). Masih ada pengelolaan sampah yang dilakukan secara individu dengan cara dibakar atau dibuang ke sungai. Sosialisasi pengelolaan sampah dengan konsep 3R oleh komunitas masyarakat ditindaklanjuti dengandibentuknya Bank Sampah di dusun Badegan, Kelurahan Bantul pada tahun 2009.

Penampungan sampah disediakan secara mandiri oleh komunitas masyarakat, kecuali di trotoar yang disediakan oleh pemerintah Kabupaten Bantul. Pengumpulan sampah dilakukan secara individu maupun komunal yang dikelola oleh petugas RT/RW. Sistem pengumpulan sampah dari sumber sampah sampai ke TPS diangkut dengan gerobak. Dari TPS sampah diangkut dengan truk sampah (dump truck dan armrool truck) ke TPA Piyungan. Untuk daerah yang berlokasi di jalan protokol, kawasan komersial dan perkantoran, sampah langsung diangkut ke TPA. Kabupaten Bantul memiliki kendaraan pengangkut sampah (dump truck) 15 buah, armrool truck 4 buah dan pickup L-300 1 buah 
dalam kondisi baik. Sistem layanan sampah terpusat yang cukup besar pada kecamatankecamatan yang termasuk kawasan perkotaan meliputi Kecamatan Bantul, Banguntapan, Sewon dan Kasihan. Sedangkan di 12 kecamatan lainnya, jumlah volume sampah terangkut lebih kecil dan berasal dari TPS pasar. Dari seluruh kecamatan, hanya Kecamatan Dlingo yang belum terlayani (Bappeda Kab.Bantul, 2010).

Tabel 1. Volume Sampah dan Sampah Terangkut Per Hari di Kabupaten Bantul

\begin{tabular}{clccccc}
\hline No & Kecamatan & $\begin{array}{c}\text { Jml TPS } \\
\text { dan } \\
\text { Kontainer }\end{array}$ & $\begin{array}{c}\text { Jumlah } \\
\text { Ritasi Truk } \\
\text { Sampah }\end{array}$ & $\begin{array}{c}\text { Volume } \\
\text { Sampah } \\
\text { perhari } \\
\left(\mathbf{m}^{3}\right)\end{array}$ & $\begin{array}{c}\text { Volume } \\
\text { Sampah } \\
\text { Terangkut } \\
\text { perhari }\left(\mathbf{m}^{3}\right)\end{array}$ & $\begin{array}{c}\text { Vol.Sampah } \\
\text { Tidak } \\
\text { Terangkut } \\
\text { perhari }\left(\mathbf{m}^{3}\right)\end{array}$ \\
\hline 1 & Srandakan & 1 & 1 & 78,59 & 1,00 & 77,59 \\
2 & Sanden & 2 & 1 & 91,14 & 2,05 & 89,08 \\
3 & Kretek & 3 & 1 & 80,69 & 5,35 & 75,34 \\
4 & Pundong & 2 & 1 & 82,36 & 1,35 & 81,01 \\
5 & Bambanglipuro & 5 & 1 & 111,97 & 3,71 & 108,26 \\
6 & Pandak & 3 & 1 & 128,66 & 1,60 & 127,06 \\
7 & Bantul & 27 & 1 & 155,51 & 33,09 & 122,42 \\
8 & Jetis & 4 & 1 & 130,09 & 1,48 & 129,08 \\
9 & Imogiri & 2 & 1 & 154,17 & 6,25 & 147,92 \\
10 & Dlingo & - & & 105,67 & - & 105,67 \\
11 & Pleret & 3 & 1 & $105 \wedge 2$ & 1,20 & 104,12 \\
12 & Piyungan & 4 & 1 & 103,46 & 4,50 & 98,96 \\
13 & Banguntapan & 8 & 1 & 227,33 & 30,06 & 197,26 \\
14 & Sewon & 26 & 1 & 203,92 & 17,70 & 186,22 \\
15 & Kasihan & 14 & 1 & 230,58 & 14,88 & 215,69 \\
16 & Pajangan & 5 & 1 & 83,10 & 3,34 & 79,76 \\
17 & Sedayu & 6 & 1 & 117,43 & 3,79 & 113,64 \\
& Jumlah & 111 & 16 & $2.190,43$ & 131,37 & $2.059,06$ \\
& & \multicolumn{2}{c}{ Persentase } & $6,00 \%$ & $94,00 \%$ \\
\hline
\end{tabular}

Sumber: Dinas Pekerjaan Umum Kabupaten Bantul, 2011

Tabel 1 menunjukkan data volume sampah terangkut terbesar di Kecamatan Bantul, Kasihan, Banguntapan, dan Sewon karena 4 kecamatan tersebut merupakan kawasan perkotaan.Proyeksi timbulan sampah di Kabupaten Bantul menggunakan standar 2-3 liter sampah tiap orangdalam sehari. Sampah di Kabupaten Bantul, baik sampah organik maupun sampah anorganik serta sampah B3, dibuang ke TPA Piyungan yang berlokasi di Desa Sitimulyo, Kecamatan Piyungan. TPA Piyungan mulai dioperasikan tahun 1995, memiliki luas 12 hektar dan kapasitas 2,7 juta meter kubik sampah. Masa pemakaian diperkirakan 10 tahun dengan asumsi prosentase daur ulang 20\%. Apabila persentase daur ulang mencapai 50\%, maka masa pemakaian bisa mencapai 13 tahun. TPA Piyungan merupakan lokasi akhir pembuangan sampah yang dihasilkan warga dari tiga kawasan perkotaan, yakni dari Kota Yogyakarta, kawasan perkotaan Kabupaten Sleman dan Kabupaten Bantul. TPA Piyungan dalam sehari menerima sekitar 350 ton sampah. TPA Piyungan dikelola melalaui Sekretariat Bersama Yogyakarta - Sleman - Bantul (Sekberkartamantul) yang memfasilitasi Kota Yogyakarta, Kabupaten Sleman dan Kabupaten Bantul dalam berkoordinasi dan menentukan kebijakan yang akan diambil dalam pengelolaan sampah di TPA Piyungan. Perjanjian kerjasama dibuat atas dasar saling membantu dan menguntungkan dalam pengelolaan operasi dan pemeliharaan prasarana dan sarana TPA dengan tujuan agar pemanfaatan, pengelolaan dan pengembangan TPA dapat dilakukan secara efektif dan efisien serta memenuhi standar teknis lingkungan. 
Tabel 2 menunjukkan jumlah volume sampah Kabupaten Bantul yang dibuang ke TPA Piyungan. Pengelolaan sampah di TPA Piyungan semula menggunakan metode sanitary landfill, yaitu dengan membuang dan menumpuk sampah di lokasi yang cekung, memadatkan sampah setelah ketinggian sampah mencapai $40 \mathrm{~cm}$ dan kemudian menutupnya dengan tanah. Sampah yang dikelola dengan metode sanitary landfill adalah sampah organik (sampah yang dapat terurai). Pada saat ini, proses pengolahan sampah di TPA Piyungan berubah menjadi control landfill karena dalam pengelolaan sampah di TPA Piyungan tidak lagi dilakukan pemisahan antara sampah organik dan anorganik. Pemilahan sampah-sampah tersebut dilakukan para pemulung dan terbatas pada sampah yang memiliki nilai ekonomi dan bisa dijual kembali. Jika tidak memiliki nilai ekonomi, sampahsampah menjadi makanan sapi dan kambing milik penduduk sekitar TPA Piyungan. Di TPA Piyungan terdapat kolam pengolahan leacheate atau lindi, pipa pengendali gas buang, sistem drainase dan lapisan kedap air. Penutupan dilakukan secara periodik untuk meminimalkan potensi gangguan lingkungan.

Tabel 2. Jumlah Volume Sampah Kabupaten Bantul yang dibuang ke TPA Piyungan

\begin{tabular}{clcccc}
\hline \multirow{2}{*}{ No. } & \multirow{2}{*}{ Bulan } & \multicolumn{3}{c}{ Berat Sampah/ bulan $(\mathbf{k g})$} \\
\cline { 3 - 6 } & & \multicolumn{2}{c}{ Tahun 2010 } & \multicolumn{2}{c}{ Tahun2011 } \\
\cline { 3 - 6 } & & Pemerintah & Swasta & Pemerintah & Swasta \\
\hline 1. & Januari & 821.770 & 11.600 & 99.3280 & 37.210 \\
2. & Februari & 786.970 & - & 87.6610 & 26.480 \\
3. & Maret & 790.270 & - & 99.6680 & 18.310 \\
4 & April & 866.850 & - & 85.1119 & 25.710 \\
5 & Mei & 898.670 & - & 83.8410 & 54.910 \\
6 & Juni & 823.790 & - & 75.8080 & 63.840 \\
7. & Juli & 869.900 & - & 82.3300 & 23.410 \\
8. & Agustus & 907.510 & - & 95.2000 & 1.402 .000 \\
9 & September & 996.130 & 42.480 & 73.8880 & 9.760 \\
10. & Oktober & 1080.530 & 22.660 & - & - \\
11. & November & 399.690 & 10.670 & - & - \\
12. & Desember & 10.156 .810 & 87.410 & 7.828 .359 & 261.032 \\
\hline
\end{tabular}

Sumber: Pengelola TPST Piyungan Bantul, 2011

Sumber-sumber sampah di Kabupaten Bantul berasal dari sampah permukiman (sampah aktivitas dapur dan kegiatan rumah tangga lainnya), sampah pasar tradisional baik sisa bahan pembungkus maupun sampah yang tidak dapat dimanfaatkan lagi, sampah medis yang berasal dari aktivitas rumah sakit,sampah industri yangmerupakan sisa-sisa aktivitas industri jenis non B3, dan sampah yang berasal dari aktivitas pejalan kaki, pengendara kendaraan maupun berasal dari pengguna jalan lainnya. Tabel 3 menunjukkan kondisi timbulan sampah berdasarkan sumber sampah di Kabupaten Bantul.

Tabel 3. Persentase Timbulan Produksi Sampah Berdasarkan Sumber Sampah

\begin{tabular}{clcc}
\hline No & \multicolumn{1}{c}{ Sumber } & Produksi sampah (m3/hari) & Persentase (\%) \\
\hline 1 & Pemukiman & 45,33 & 40 \\
2 & Pasar Tradisional & 39,67 & 35 \\
3 & Pasar Modern & 0 & 0 \\
4 & Hotel dan penginapan & 2,27 & 2 \\
5 & Rumah sakit & 4,53 & 4 \\
6 & Industri (non B3) & 4,53 & 4 \\
\hline
\end{tabular}




\begin{tabular}{clcc}
\hline No & \multicolumn{1}{c}{ Sumber } & Produksi sampah (m3/hari) & Persentase (\%) \\
\hline 7 & Urban & 14,73 & 13 \\
8 & Lain-lain & 2,27 & 2 \\
& Jumlah & 113,33 & 100 \\
\hline
\end{tabular}

Sumber: Dinas Pekerjaan Umum Kabupaten Bantul, 2011

Partisipasi masyarakat di Kabupaten Bantul dalam pengelolaan sampah berupa penanganan sampah di rumah masing-masing dilakukan dengan cara ditimbun atau dibakar, terutama pada permukiman dengan tingkat kepadatan penduduk yang rendah. Hanya sebagian kecil masyarakat yang melakukan pengelolaan sampah dengan konsep 3R. Pengelolaan sampah rumah tangga sudah ada keterlibatan perempuan dari tingkat rumah tangga sampai tingkat kelurahan dan kecamatan yang tergabung dalam 28 kelompok pengelola sampah. Kelompok masyarakat pengelola sampah terjelaskan di Tabel 4.

Berdasarkan pengamatan, ditemukan permasalahan timbulan sampah. Sampah rumah tangga dan komersial cenderung dinamis,sampah basah relatif berkurang sedangkan sampah kertas, kaca, plastik, logam, dan benda lain bertambah. Sampah yang belum dipisahkan menyebabkan sampah menjadi kurang ekonomis dansampah yang dihasilkan meningkat dan belum diikuti dengan kesadaran untuk menangani sampah dari sumbernya. Pewadahan dan pengumpulan sampah dilakukan pada wilayah yang padat penduduk, terutama di 4 kecamatan yang termasuk kawasan perkotaan (Kecamatan Bantul, Sewon, Kasihan dan Banguntapan). Kecamatan Dlingo yang tergolong kawasandengan tingkat kepadatan penduduk rendah, pengelolaan sampah dilakukan oleh masing-masing keluarga.

Pelaksanaan sistem pengelolaan sampah di Kabupaten Bantul belum mencapai target karena peningkatan jumlah rumah tangga dan sumber sampah lebih besar dibandingkan peningkatan jumlah cakupan pelayanan pengangkutan sampah. Hal ini menyebabkan pemukiman yang belum memiliki pelayanan persampahan cenderung membuang sampah secara ilegal. Transfer depo yang diharapkan dapat mempercepat pengangkutan sampah, ternyata sebagian masih berfungsi sebagai tempat pembuangan sampah sementara (TPS) karena waktu kedatangan truk pengangkut sampah dan gerobak pengumpul sampah tidak bersamaan. Selain itu, sarana pengangkutan sampah masih belum sebanding dengan volume sampah yang dihasilkan dari seluruh Kabupaten Bantul. Permasalahan lainnya yaitu masih bercampurnya sampah organik dan anorganik serta desain TPS yang belum mendukung kemudahan pemuatan sampah ke bak truk sampah. Sampah rumah tangga di 28 kelompok pengelola sampah sudah dibuat kompos secara tradisional dan berbagai produk daur ulang, namun masih terkendala pemasaran produk. Sistem daur ulang dan penggunaaan kembali yang efektif di 28 kelompok belum mampu berkembang sesuai rencana karena baru sebagian kecil penduduk yang memilah sampah sebelum dibuang.

Berdasarkan UU Nomor 18 Tahun 2008 tentang Pengelolaan Sampah, terdapat kelompok utama pengelolaan sampah di Kabupaten Bantul, yang bertujuan melakukan kegiatan pengurangan sampah yang terdiri dari pembatasan terjadinya sampah, guna-ulang dan daur-ulang. Penanganan sampah terdiri dari pemilahan dalam bentuk pengelompokan dan pemisahan sampah sesuai dengan jenis, jumlah, dan sifat sampah. Pengumpulan dalam bentuk pengambilan dan pemindahan sampah dari sumber sampah ke tempat penampungan sementara atau tempat pengolahan sampah terpadu. Pengangkutan dalam bentuk membawa sampah dari sumber dan tempat penampungan sampah sementara atau dari tempat pengolahan sampah terpadu menuju ke tempat pemrosesan akhir, Pengolahan dalam bentuk mengubah karakteristik, komposisi, dan jumlah sampah, serta pemrosesan akhir sampah dalam bentuk pengembalian sampah atau residu hasil pengolahan sebelumnya ke media lingkungan secara aman. Bagian sampah atau residu dari kegiatan pengurangan sampah yang masih tersisa selanjutnya dilakukan pengolahan maupun penimbunan. 
Tabel 4. Kelompok Masyarakat Pengelola Sampah (3R)

\begin{tabular}{|c|c|c|c|c|c|c|c|c|c|}
\hline \multirow{2}{*}{ No } & \multirow{2}{*}{ Nama Kelompok } & \multirow{2}{*}{ Lokasi } & \multirow{2}{*}{$\begin{array}{c}\text { Jumlah } \\
\text { Pengelola } \\
\text { (orang) }\end{array}$} & \multirow{2}{*}{$\begin{array}{c}\text { Rumah Tangga } \\
\text { Peserta } \\
\text { (KK) }\end{array}$} & \multirow{2}{*}{$\begin{array}{c}\text { Bentuk Pengelolaan } \\
\text { 3R }\end{array}$} & \multirow{2}{*}{$\begin{array}{c}\text { Identifikasi Usaha } \\
\text { dari Recycle \& } \\
\text { Reuse }\end{array}$} & \multicolumn{3}{|c|}{$\begin{array}{c}\text { Rerata Pengelolaan 3R } \\
\text { per bulan dalam kg/bulan }\end{array}$} \\
\hline & & & & & & & $\begin{array}{c}\text { Plastik } \\
\text { (kg) }\end{array}$ & $\begin{array}{c}\text { Kertas/ } \\
\text { Karton }(\mathbf{k g})\end{array}$ & $\begin{array}{c}\text { Logam } \\
(\mathrm{kg})\end{array}$ \\
\hline 1 & Asolla & Serut,Palbapang & 5 & 32 & Daur ulang & Kerajinan & 15 & 35 & 0.5 \\
\hline 2 & Idelweis & Serut,Palbapang & 17 & 36 & Organik & Pupuk organik & \multicolumn{3}{|c|}{ Bahan baku organik $1.500-2.000$} \\
\hline 3 & Gemah Ripah & Badegan,Bantul & 8 & 1 pedukuhan & Bank Sampah & Kerajinan\&Kompos & 140 & 144 & 12.5 \\
\hline 4 & Milah Rejeki & Sabrang,Bambanglipuro & 12 & 60 & Bank Sampah & Pengepulan & $30-60$ & 40 & 10 \\
\hline 5 & Miguno & Plumbungan,Bambanglipuro & 9 & 1 pedukuhan & Bank Sampah & Pengepulan & 86 & 150 & 11 \\
\hline 6 & Sri Asih & Sribitan,Bangunjiwo & 11 & 1 pedukuhan & Bank Sampah & Pengepulan & 120 & 200 & 30 \\
\hline 7 & Sehat Ceria & Selokambang,Gatak II Tamantirto & 9 & 2RT (74) & Bank Sampah & Pengepulan & 133 & 80 & 19 \\
\hline 8 & Suket Teki & Rukeman,Tamantirto & 8 & 2RT (83) & Bank Sampah & Pengepulan & 30 & 42 & 7 \\
\hline 9 & Sambel Trasi & Ngebel,Tamantirto & 9 & 60 & Bank Sampah & Pengepulan & 20 & 70 & 5 \\
\hline 10 & Tlogo Makmur & Tlogo, Tamantirto & 7 & 53 & Bank Sampah & Pengepulan & 20 & 20 & 5 \\
\hline 11 & Tegal Wangi & Tegal Wangi,Tamantirto & 6 & 44 & Bank Sampah & Pengepulan & 15 & 40 & 3 \\
\hline 12 & Tundan & Tundan,Tamantirto & 7 & 62 & Bank Sampah & Pengepulan & 45 & 70 & 10 \\
\hline 13 & Ngudi Asri & Sanggrahan,Ngestiharjo & 6 & 1Desa & Penanganan Sampah & Pengepulan & 400 & 800 & 50 \\
\hline 14 & Soragan Bersih & Soragan,Ngestiharjo & 11 & \multirow{2}{*}{$\begin{array}{l}1 \text { Pedukuhan } \\
1 \text { Pedukuhan } \\
\text { (138) }\end{array}$} & \multirow{2}{*}{$\begin{array}{c}\text { Pengepulan } \\
\text { Daur Ulang/Bank } \\
\text { Sampah }\end{array}$} & Pembangunan & 200 & 400 & 40 \\
\hline 15 & Sampah Berkah & Jurug,Argosari,Sedayu & 12 & & & Pengepulan & 30 & 60 & 10 \\
\hline 16 & Mekar Abadi & Metes,Argorejo,Sedayu & 5 & 1 Kecamatan & Pengepulan & Pengepulan & 8.000 & 2.000 & 150 \\
\hline 17 & Bank Sampah 45 & Metes,Argorejo,Sedayu & 9 & 1RT (58) & Bank Sampah & Pengepulan & 40 & 110 & 18 \\
\hline 18 & Indra Paramiha/Radite & Metes,Argorejo,Sedayu & 4 & $1 \mathrm{RT}$ & Daur Ulang & Kerajinan & 22 & 0 & 0 \\
\hline 19 & Sumber Rejeki & Bulus Wetan,Jetis & 14 & 3RT (124) & Daur Ulang & Kerajinan/Pupuk & 45 & 30 & 7 \\
\hline 20 & Saka Madani & Kweni,Panggungharjo,Sewon & 10 & 4RT (181) & Pengepulan & Pengomposan & 63 & 140 & 20 \\
\hline 21 & Bersih Menuju Sehat & Salakan,Potorono,Banguntapan & 18 & 1 Pedukuhan & Pengepulan & Pengomposan & 90 & 200 & 20 \\
\hline 22 & Tamanan & Tamanan,Banguntapan & 6 & $1 \mathrm{RT}$ & Bank Sampah & Pengepulan & 20 & 65 & 5 \\
\hline 23 & Resik & Saman,Bangunharjo,Sewon & 5 & 1RT & Bank Sampah & Pengepulan & 19 & 35 & 0 \\
\hline 24 & Dadi Arto & Singosaren,Banguntapan & 7 & 2RT (71) & Bank Sampah & Pengepulan & 33 & 75 & 7 \\
\hline 25 & Kauman Baru & Kauman,Pleret & 13 & 1 Perumahan & $\begin{array}{l}\text { Pengelolaan } \\
\text { Lingkungan }\end{array}$ & Pengepulan & 30 & 80 & 11 \\
\hline 26 & Makaryo Mulyo & Segoroyoso,Pleret & 14 & 1 Pedukuhan & Pengepulan/Pemilahan & Pupuk & 30 & 55 & 12 \\
\hline 27 & Mandiri & Terong,Dlingo & 7 & 2RT & Bank Sampah & Pengepulan & 30 & 70 & 14 \\
\hline 28 & Asri Setiti & Pokoh,Dlingo & 6 & $\begin{array}{c}1 \text { Pedukuhan } \\
(86)\end{array}$ & Organik & Briket & & $400 \mathrm{~kg}$ daun $\mathrm{j}$ & \\
\hline
\end{tabular}

Sumber: Paguyuban Kelompok Pengelola Sampah “Merti Boemi”, 2011 
Penanganan sampah melalui konsep 3R di Kabupaten Bantul meliputi upaya agar sampah yang dihasilkan sesedikit mungkin di tingkat rumah tangga dengan cara pemakaian materi yang berpotensi menimbulkan sampah, pemanfaatan sampah secara langsung dan pengolahan sampah menjadi bahan baku maupun sebagai sumber energi. CommunityBased Solid Waste Management atau pengelolaan sampah berbasis masyarakat telah diterapkan oleh 28 kelompok di Kabupaten Bantul. Masyarakat sebagai pelaku utama dalam pengelolaan sampah mulai dari merencanakan, membentuk, menjalankan dan mengatur pengelolaan sampah. Tujuannya yaitu untuk mengurangi dan menangani sampah rumah tangga yang dihasilkan secara sistematik, terpadu, dan berkelanjutan. Pengelolaan sampah berbasis masyarakat di Kabupaten Bantul memiliki karakteristik: a) independen, tidak bergantung pada pelayanan pemerintah, b) produktif, menghasilkan manfaat (penghasilan, efisiensi biaya pengelolaan sampah), c) terpadu, mengelola sampah rumah tangga dengan konsep 3R, d) ramah lingkungan, aman bagi lingkungan.

Dengan dukungan sosialisasi dari BLH Kabupaten Bantul, penerapanCommunityBased Solid Waste Management menjadi pilot project di Kabupaten Bantul. Peran perempuan dalam 28 kelompok pengelola sampah di Kabupaten Bantul dimulai dari tahap penanganan timbulan sampah organik yang biasanya berasal dari sampah dapur dan daun. Kategori sampah tersebut dimasukkan ke dalam komposter yang ada di setiap rumah oleh ibu-ibu rumah tangga. Sedangkan sampah anorganik seperti plastik, kertas dan botol dikumpulkan dalam wadah yang berbeda sesuai dengan jenisnya yang selanjutnya dikumpulkan lagi di tempat penampungan sementara milik desa. Sampah anorganik yang laku jual akan dibeli oleh pengepul sedangkan yang tidak laku jual akan didaur ulang menjadi kerajinan oleh para ibu-ibu anggota kelompok (paguyuban) Merti Boemi. Sampah yang tidak dapat dikelola akan diangkut ke TPA Piyungan oleh petugas swadaya.

Community-Based Solid Waste Management dengan kegiatan pengelolaan sampah yang menggunakan konsep "bank sampah" Badegan di Kabupaten Bantul dilakukan dengan cara memilah sampah dari skala rumah tangga. Tujuan memilah sampah ini untuk mendapatkan sampah anorganik layak jual yang bisa ditabung di "bank sampah" Badegan. Sampah yang sudah dipilah dibawa sendiri oleh masyarakat ke "bank sampah" Badegan. Sampah organik dimasukkan ke komposter rumah tangga dansampah anorganik yang tidak layak jual diangkut oleh petugas.

Masyarakat penabung sampah pada kelompok (paguyuban) Merti Boemi disebut nasabah. Setiap nasabah sampah memiliki tempat penampungan yang sudah memiliki identitas nama dan nomor rekening pemilik sehingga memudahkan petugas memilah tabungan sampah setiap nasabah yang akan diambil oleh pengepul sampah. Setelah tempat terisi penuh, petugas "bank sampah" Badegan menghubungi pengepul. Selanjutnya pengepul akan menaksir harga tiap kantong untuk kemudian dicocokkan dengan bukti setoran nasabah. Selain nasabah, terdapat peran pemulung dalam pengelolaan sampah di 28 kelompok (paguyuban) Merti Boemi. Proses daur ulang yang dilakukan oleh pemulung meliputi pemisahan atau pengelompokan sampah. Pemulung memungut sampah anorganik yang masih bernilai ekonomis dan dapat didaur ulang sebagai bahan baku industri atau langsung diolah oleh ibu-ibu anggota kelompok menjadi barang jadi yang dapat dijual.

Sampah anorganik yang diambil oleh pemulung merupakan sampah yang belum dapat ditangani oleh Pemerintah Kabupaten Bantul. Hal ini menunjukkan bahwa kegiatan pemulung memberi kontribusi dalam penanganan sampah.Di Kabupaten Bantul, tingkat daur-ulang baik melalui usaha pemulung maupun usaha daur ulang di tingkat rumah tangga, serta pengomposan baru sebesar 8,1\%. Pemisahan sampah oleh pemulung relatif masih sedikit (kurang dari $2 \%$ ) dibandingkan dengan total volume sampah yang terkumpul di TPS. Sampah di TPA yang diambil juga memiliki kualitas yang lebih rendah dibandingkan di TPS tetapi memiliki persentase yang lebih besar (5\%) dari volume sampah yang tiba di TPA. Secara bertahap, konsep pengolahan sampah secara terpadu telah 


\section{Studi Pengelolaan Sampah Berbasis Komunitas Pada Kawasan Permukiman ...}

diterapkan dalam skala terbatas meskipun umumnya tidak berlangsung lama. Perilaku memilah sampah berdasarkan jenisnya telah diterapkan oleh 28 kelompok masyarakat yang sudah memulai dan merasakan manfaat secara langsung.

\section{Kesimpulan dan Saran}

Pendekatan partisipasi masyarakat relevan dipergunakan pada wilayah permukiman di Kabupaten Bantul. Pendekatan tersebut secara bertahap mampu mendorong masyarakat untuk bersedia terlibat, melakukan dan merasakan manfaat. Pendekatan partisipasi masyarakatjuga mampu mendorong partisipasi masyarakat dalam pengelolaan sampah sejak dari sumbernya. Penggunaan pendekatan partisipasi masyarakat dalam pengelolaan sampah di Kabupaten Bantul mendorong pengatasan permasalahan berdasarkan kondisi masyarakat. Kelemahan, potensi, peluang dan tantangan yang ditawarkan mengacu kepada kondisi masyarakat. Masyarakat yang berdaya dalam pengelolaan sampah di Kabupaten Bantul mampu mengorganisir dalam kegiatan bersama untuk memecahkan permasalahan sampah mereka, dan bentuk kesadaran dalam menanggapi permasalahan sampah atas dasar kepentingan bersama.

\section{Ucapan Terima Kasih}

Ucapan terima kasih disampaikan kepada Bappeda Bantul atas dukungan selama Penyusunan Studi Strategi Pengembangan Permukiman Infrastruktur Perkotaan (SPPIP) Kabupaten Bantul, 2011.

\section{Daftar Pustaka}

Amalia S., Siti H., \& Shabila A. (2013). Macroergonomic approach for improving the municipal waste management system in Jakarta. International Journal of Innovation, Management and Technology, 4(6), 560-564. doi:10.7763/IJIMT.2013.V4.461.

Artiningsih, N. K .A., Hadi, S. P., \& Syafrudin. (2012). Peran serta masyarakat dalam pengelolaan sampah rumah tangga. Jurnal Serat Acitya, 1(2), 107-114.

Bappeda Kabupaten Bantul. (2010). Buku putih sanitasi Kabupaten Bantul. Kabupaten Bantul: Bappeda Kabupaten Bantul.

BLH Kabupaten Bantul. (2011.) Laporan periodik per bulan sampah harian Kabupaten Bantul. Kabupaten Bantul: BLH Kabupaten Bantul.

Dinas Pekerjaan Umum Kabupaten Bantul. (2011). Data persampahan. Kabupaten Bantul: DPU Kabupaten Bantul.

Dwiyanto, B. M. (2011). Model peningkatan partisipasi masyarakat dan penguatan sinergi dalam pengelolaan sampah perkotaan. Jurnal Ekonomi Pembangunan, 12(2), 239-256. doi:10.23917/jep.v12i2.196.

Faizah. (2008). Pengelolaan sampah rumah tangga berbasis masyarakat (Unpublished master's thesis). Program Pascasarjana Universitas Diponegoro, Semarang.

Haryono. (2015). The identification of city solid waste management based on the active participation of families and trash pickers. Academic Research International, 6(1), 184-191.

Jati, T. K. (2013). Peran Pemerintah Boyolali dalam pengelolaan sampah lingkungan permukiman perkotaan (Studi kasus Perumahan Bumi Singkil Permai), Jurnal Wilayah dan Lingkungan, 1(1), 1-16. doi:10.14710/jwl.1.1.1-16.

Mifbakhuddin, Salawati, T., \& Kasmudi, A. (2010). Gambaran pengelolaan sampah rumah tangga tinjauan aspek pendidikan, pengetahuan dan pendapatan perkapita di RT 6 RW 1 Kelurahan Pedurungan Tengah Semarang. Jurnal Kesehatan Masyarakat Indonesia, 6(1), 1-14. 
Paguyuban Kelompok Pengelola sampah “Merti Boemi”. (2011). Data kegiatan pengelolaan sampah. Kabupaten Bantul.

Pemerintah Republik Indonsia. Undang-undang Nomor 18 Tahun 2008 tentang Pengelolaan Sampah. Jakarta: Sekretariat Negara Republik Indonesia.

Pengelola TPST Piyungan Bantul. (2011). Data persampahan. Kabupaten Bantul.

Riswan, H. R. S., \& Hadiyarto, A. (2011). Pengelolaan sampah rumah tangga di Kecamataan Daha Selatan. Jurnal Ilmu Lingkungan, 9(1), 31-38. doi:10.14710/jil.9.1.31-38.

Ruslinda, Y., Indah, S., \& Laylani, W. (2012). Studi timbulan, komposisi dan karakteristik sampah domestik Kota Bukittinggi. Jurnal Teknik Lingkungan, 9(1), 1-12 .

Yogiesti, V., Hariyani S., \& Sutikno F. R. (2010). Pengelolaan sampah terpadu berbasis masyarakat Kota Kediri. Jurnal Tata Kota dan Daerah, 2(2), 95-102.

Widyatmoko, \& Moerdjoko, S. (2002), Menghindari, mengolah dan menyingkirkan sampah. Jakarta: Abadi Tandur. 
38 Studi Pengelolaan Sampah Berbasis Komunitas Pada Kawasan Permukiman ...

JURNAL WILAYAH DAN LINGKUNGAN, 3 (1), 26-38 